\title{
Применение программируемого источника питания ITECH IT6000С для испытаний движителя с эффектом Холла
}

\author{
М. Писковацков ${ }^{1}$
}

УДК 621.314.6 | ВАК 05.11.01

\begin{abstract}
При проведении испытаний движителя с эффектом Холла, который часто используется для приведения в движение космических аппаратов, необходим источник питания высокой мощности. Компания ITЕСН предлагает двунаправленные программируемые источники питания постоянного тока серии IT6000С, которые полностью соответствуют требованиям и условиям такого рода испытаний. Эти устройства с возможностью регенерации энергии содержат в одном корпусе источник питания и электронную нагрузку, обеспечивают выходную мощность до 144 кВт (при параллельном подключении - до 1,152 МВт), выходной ток - до 2040 А. Рассмотрим особенности испытаний перспективной двигательной установки для космических аппаратов с использованием данной модели источника питания.
\end{abstract}

Д вижитель с эффектом Холла представляет собой ионный двигатель, в котором пропеллент (инертное газообразное химическое вещество) ускоряется под действием электрического поля. Эффект Холла достигается посредством магнитного поля, препятствующего осевому движению электронов, необходимых для ионизации пропеллента и эффективного ускорения ионов, обеспечивающего тягу. Это передовое электрическое движительное устройство широко используется для позиционирования, межорбитальных маневров и / или сохранения орбиты спутников. Благодаря таким преимуществам, как простая структура, высокие удельный импульс и эффективность, устройство относится к перспективным для будущих дальних космических полетов и дальнейшего развития космонавтики

Поскольку движители с эффектом Холла выполняют чрезвычайно важные задачи в составе оборудования космического аппарата, требуется проведение ряда сложных испытаний для обеспечения стабильности и надежности всей системы.

При выполнении теста для межорбитального маневра космической станции на анод и/или катод вакуумной камеры движителя с эффектом Холла подается питание постоянного тока. После успешного запуска движителя электроны в циркулирующем токе Холла ионизируют бортовое топливо (инертный газ ксенон)

Компания "Диполь", руководитель направления измерительного оборудования общего назначения, mvp@dipaul.ru. и создают ионизированную плазму. Затем электрическое поле выталкивает ксеноновую плазму в перпендикулярном направлении и выводит ее на сверхвысокой скорости вовне через сопло, создавая тягу (рис. 1). Требования к источнику питания (ИП) остаются крайне высокими на протяжении всего тестирования. Как и все этапы испытаний, процесс ионизации может пройти гладко только при успешном запуске движителя

На этапе тестирования выходной ток ИП достигает очень высоких значений, что вызывает проблемы, обусловленные превышением допустимой мощности ИП.

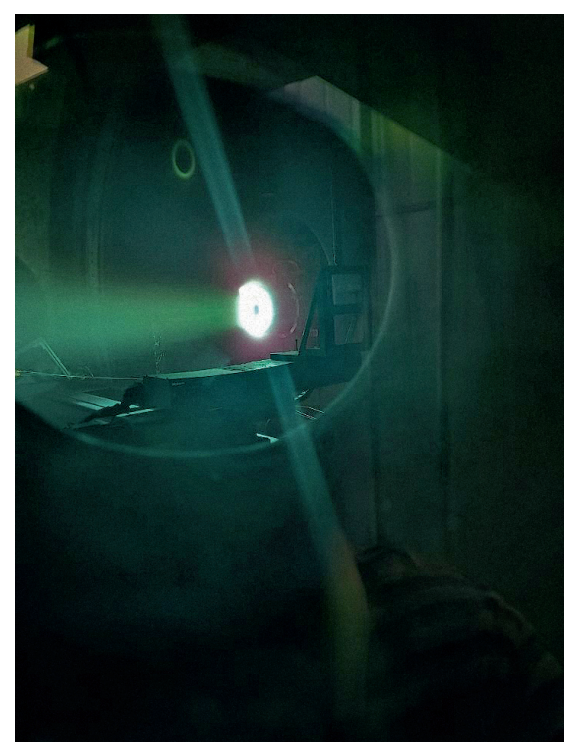

Рис. 1.

Испытания движителя с эффектом Холла мощностью $10 \mathrm{kBT}$ (500 B/20 A) в вакуумной камере 


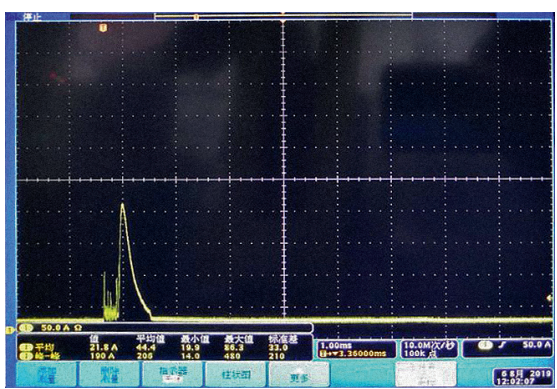

Рис. 2.

Осциллограмма выброса тока при запуске движителя с эффектом Холла

В то же время в процессе тестирования ИП должен обеспечивать высокую стабильность и точность. Для проведения испытаний компания ITECH предложила заказную конфигурацию программируемого двунаправленного ИП постоянного тока серии IT6000C, которая соответствует всем требованиям

Следует отметить ряд преимуществ этой серии ИП при проведении испытаний движителя с эффектом Холла.

Первое преимущество состоит в том, что IT6000С обеспечивает увеличенный допуск превышения мощности во время переходного процесса. Например, при запуске движителя мощностью 10 кВт (500 В/20 А) ток нагрузки достигает 180 А (рис. 2). При превышении максимального предела тока в источнике питания срабатывает защита от перегрузки, которая автоматически отключает выход, и движитель не успевает произвести запуск. Серия IT6000С расширяет возможности переходной избыточной мощности на 10 мс, что достаточно для запуска движителя

Второе преимущество - возможность регулирования времени защиты ИП серии ITECH IT6000C. В процессе тестирования время защиты достаточно короткое и для типовых ИП составляет 20 мс. IT6000С оснащен комплексом защит, в том числе защитой от превышения напряжения (OVP), скачков тока ( \pm OCP), перегрузки по суммарной мощности ( \pm ОРР) и от перегрева (ОТР). Предусмотрена также защита от снижения мощности и антисекционирование. Пользователи могут настраивать время задержки защиты. Для успешного запуска движителя достаточно установить значение задержки, равное 10 мс. В случае превышения установленного времени задержки выход ИП автоматически отключается.

Еще одно преимущество серии IT6000C - высокая и стабильная выходная мощность. При необходимости можно увеличить выходную мощность путем параллельного включения нескольких ИП, что расширяет возможности будущих проектов.

Серия IT6000С обеспечивает двухквадрантный режим работы, устройство может как передавать, так и потреблять ток. ИП отличается высокой удельной мощностью (18 кВт) в компактном корпусе высотой всего 3U. Максимальное выходное напряжение составляет 2250 В в режиме "ведущий-ведомый» с усредненным распределением тока. Максимальная мощность при параллельном включении источников питания достигает 1,152 МВт.

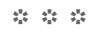

Компания ITECH предлагает комплексные и надежные решения для испытаний в различных областях, в частности для тестирования перспективных двигателей для космических аппаратов. Официальный представитель ITECH в Российской Федерации и Казахстане - компания "Диполь».

\section{КНИГИ ИЗДАТЕЛЬСТВА "ТЕХНОСФЕРА"}

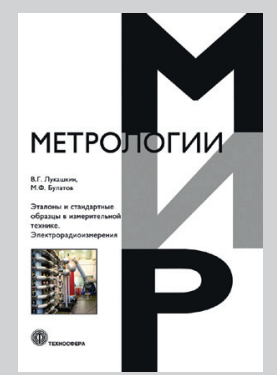

Цена 840 руб.
ЭТАЛОНЫ И СТАНДАРТНЫЕ ОБРАЗЦЫ В ИЗМЕРИТЕЛЬНОЙ ТЕХНИКЕ. ЭЛЕКТРОРАДИОИЗМЕРЕНИЯ Лукашкин В. Г., Булатов М.Ф.

Издание осуществлено при финансовой поддержке Федерапьного агентства по печати и массовым коммуникациям в рамках Федерапьной целевой программы «Культура России (2012-2018 годы)"

В книге рассмотрены общие вопросы метрологического обеспечения и единицы физических величин. Изложены основные задачи технических средств метрологического обеспечения в области электрорадиоизмерений. Даны оценки погрешности и неопределенности первичных и рабочих эталонов.

Книга может быть полезна студентам и аспирантам при выборе и обосновании эталонной базы в области электрорадиоизмерений, а также специалистам, занимающимся вопросами разработки, производства и оценки качества средств измерений, контроля и испытаний.

\section{КАК ЗАКАЗАТЬ НАШИ КНИГИ?}

凶125319, Москва, а/я 91; †+7 495 234-0110; @+7 495 956-3346; knigi@technosphera.ru, sales@technosphera.ru 